\title{
RESEARCH OF THE INFLUENCE OF LOW-FREQUENCY AND HIGH-FREQUENCY ACTIONS ON PROCESSING OF TECHNOLOGICAL ENVIRONMENTS
}

\author{
Ivan Nazarenko \\ Department of machinery and equipment of technological processes \\ Kyiv National University of Construction and Architecture \\ 31 Povitroflotsky ave., Kyiv, Ukraine, 03037 \\ i_nazar@i.ua \\ Oleksandr Luhovskyi \\ Departament of Applied Hydro-Aeromechanics and Mechatronics \\ National Technical University of Ukraine «Igor Sikorsky Kyiv polytechnic institute» \\ 37 Peremohy ave., Kyiv, Ukraine, 03056 \\ atoll-sonic@ukr.net \\ Iryna Bernyk \\ Departament of Applied Hydro-Aeromechanics and Mechatronics \\ National Technical University of Ukraine «Igor Sikorsky Kyiv polytechnic institute» \\ 37 Peremohy ave., Kyiv, Ukraine, 03056 \\ iryna_bernyk@i.ua \\ Anatoly Svidersky \\ Department of machinery and equipment of technological processes \\ Kyiv National University of Construction and Architecture \\ 31 Povitroflotsky ave., Kyiv, Ukraine, 03037 \\ tolyasv@ukr.net
}

\begin{abstract}
The processing of various vibrational low-frequency and cavitation high-frequency actions by their rheological properties is studied. A mathematical model of the motion of particles of a technological environment is determined taking into account the different nature of the dissipative forces. Two kinds of frictional forces are applied: dry at the first stage of changing the constituents of the mixture and viscous at the second, final stage of compaction of the mixture. The obtained analytical dependencies reveal the physical picture of the behavior of particles and the technological environment as a whole. The key stages of compaction to account for dry and viscous friction between the components of materials are described. It is revealed that processing at low frequencies reduces energy costs. Taking into account in vibroacoustic processes the contribution of higher harmonics greatly accelerates the process of cavitation. This is a fundamentally new result and the idea of the possibility of obtaining an effect for creating new materials. The obtained amplitudes and frequencies of oscillations of both low-frequency and high-frequency modes open a new direction in technologies for improving the quality of material processing. The main modes and parameters of vibrational and acoustic action for effective implementation of material processing processes are determined. The obtained results are applied at definition of rheological and technological parameters at various stages of processing of materials. The basic directions of quality improvement of processing environments are formulated.
\end{abstract}

Keywords: technological environment, processing stages, properties, low-frequency vibrating, high-frequency cavitation processes.

\section{Introduction}

Modern trends in the development of technologies for processing technological environments (grinding, mixing, compaction, emulsification, etc.) are aimed at finding new effective solutions. Due to the fact that in modern conditions, there are requirements to reduce energy costs, improve the quality of new obtained materials, and ensure environmental compatibility of processes. These requirements are not fully provided by low-frequency and high-frequency processing technologies 
common in various industries. Thus, in vibration systems operating at low frequencies, the potential for improving efficiency is exhausted. They work in a resonant mode, which is characterized by high energy costs. Existing methods for assessing the influence of vibration effects on the processing of materials are based on taking into account their constant, unchanged characteristics. Such approaches do not disclose the essence of the material processing processes. The lack of refined models does not solve the problems of reliable evaluation of the influence of vibration actions on processing processes of technological environments. According to the high-frequency actions of environments processing using the example of cavitation, let's have the following. Practically there are no studies of the interaction of the causative agent of the oscillations and the environment. A joint study of these technologies of the effect of parameters on processing processes is due to the following. This is a method of transferring energy from the pathogen to the environment and the wave process of propagation of energy in the environment. The difference lies in the different numerical values of the amplitude-frequency spectrum of the action on the processing environment and the designs of the exciters of the oscillations. Therefore, the problem arises of studying the physics of the processing of materials on the basis of a change in their properties. So, regardless of the type of processing low-frequency or high-frequency action on the technological environment, the problem is common. Its solution is a topical task. It consists in choosing the physical and mathematical models and determining on this basis the parameters of the influence of the parameters of the working process.

\section{Literature review and problem statement}

Vibration processes are used in various industries to perform a wide range of different technological operations for processing materials. This is due to the ability of vibration to significantly change the properties of materials. The theoretical basis for describing vibration is the classical theory of mechanical oscillations and the theory of continuous environments. The greatest application of vibrational processes is found in the processes of compaction of building mixtures [1]. To implement these processes, harmonious modes are predominantly used [2]. The frequency range of the action of exciters for compaction of construction mixtures is in the range of 15$200 \mathrm{~Hz}$. Amplitude range in the range $0.1-1.5 \mathrm{~mm}$. Such regime narrows the possibilities to compact various building mixes. The physics of the process of compaction of the mixture is not considered. In work [3] it is noted that the compaction should be checked for compliance with standard modes and real. However, the lack of an assessment of the interaction between the causative agent of the oscillations and the environment does not guarantee the provision of the parameters specified by the technology. There is no description of the motion process of the constituents of the environment, either individual particles or the possible motion of the environment as a continuous one. In most modes, the amplitude of the oscillations, like the frequency, can vary. Therefore, it is possible to state that there is a problem of finding solutions on a new model of the notion of a process that is adequate to the real. The high-frequency modes of processing include the acoustic method [4]. Cavitation operating modes should significantly differ from the vibration values of the parameter: sound frequencies $\left(\mathrm{f}=20-2010^{3} \mathrm{~Hz}\right)$ and ultrasonic $-\left(\mathrm{f}=2010^{3}-10^{8} \mathrm{~Hz}\right)$. Amplitude range is in the range $(0.1-1.5) 10^{-3} \mathrm{~mm}$.

However, changes in density, viscosity, sound speed, absorption coefficient, wave resistance are not taken into account. In addition, as in low-frequency systems, the process of processing by acoustic cavitation should take into account the interaction of the environment and the cavitation apparatus. It creates a cavitation region in a dispersed liquid environment [5]. Such technologies allow creating new substances and environments [6]. The appearance of intense shock waves [7] does not reveal the process of interaction. Attention is focused on the possible formation of pulsating gas-vapor bubbles, the size of which is less than the critical one. The degree of collapse of the bubbles is small and sometimes even absent [8]. It is noted in [9] that the process of slamming occurs without the appearance of shock waves. In [10], the effect of viscosity without indicating the interaction with the environment of energy sources is noted. Even there are considerations about the creation of a chaotic unstable motion [11]. 
Attention is paid to the influence of two frequencies, as noted in [12]. The presence of certain bubbles in the cavitation area depends on the parameters and regimes in the current process of cavitation development. An important conclusion is that an undeniable fact of the action of acoustic cavitation is a significant change in the rheological properties of the cavitating environment and parameters. At the same time, this change in properties is not taken into account either in certain parameters or in the calculation models. By this time there are no studies of the specific effect of the environment on the movement of the cavitator. There are no studies of the processing process with a change in the time parameters of the pathogen and changes in the environment. Such interaction is a new concept for evaluating not only the parameters of the process, but also the possible creation of fundamentally new regimes and designs of exciters. Based on the analysis, the problem of determining such parameters and regimes is not solved. The practical task is determination of the physics of the process that takes place at different stages of processing the technological environment.

\section{The aim and objectives of research}

The aim of research is studying the process of motion, both individual particles and a continuous environment, to determine the effect of low-frequency and high-frequency actions on it.

To achieve this aim, the following tasks are set:

1. To develop a mathematical model and describe the motion of particles and the environment as a whole for actions of a different nature.

2. To investigate and determine the main parameters of influence on processes of environments processing.

3. To propose a direction of purposeful use of low-frequency and high-frequency methods for processing environments with a given process efficiency.

\section{Methodology for studying environments processing by low-frequency and high-frequency actions}

The method of carrying out the research provides for carrying out analytical and experimental studies. The idea of considering two stages of compaction is advanced, the adequacy of which is described by the real process of processing by discrete and continual models. The choice of model depends on the stage of the process. When implementing low-frequency oscillations, the process of compaction of a concrete mixture is considered and the following hypotheses are accepted. The first stage is modeled by the discrete movement of the particles, since the concrete mixture is a random, air-filled structure. After the completion of the first stage, the structure changes and at the second stage becomes a continuous environment. Therefore, its description is determined by the continuum model. The second hypothesis is that the difference in models at different stages requires different values of the parameters and an estimation of their influence at each stage.

The scheme of stages proposed by the authors (Fig. 1) reveals a visual representation not only of the essence of the process, but also reveals the physics of the process. Depending on the characteristics of the processes (Fig. 1), in the second stage, various rheological models, in which certain properties dominate, can be used. Therefore, in theoretical studies, two models are considered. The first stage of theoretical studies of the environment condensation process is the construction of a mathematical model of the motion of a particle in environment. The second stage is the development of a mathematical model for the motion of a continuous environment. Experimental studies are devoted to comparison of manufactured concrete samples according to standard and research parameters.

At theoretical researches of cavitational processes of processing of technological environments the following idea is put forward. Contact pressure on the edge of the "cavitator-environment" system is a key parameter of the evolution of gas and air bubbles in an acoustic field. Therefore, in assessing the influence of high-frequency actions on the processing environment, the evaluation of contact pressure is the basis of the carried out studies. 


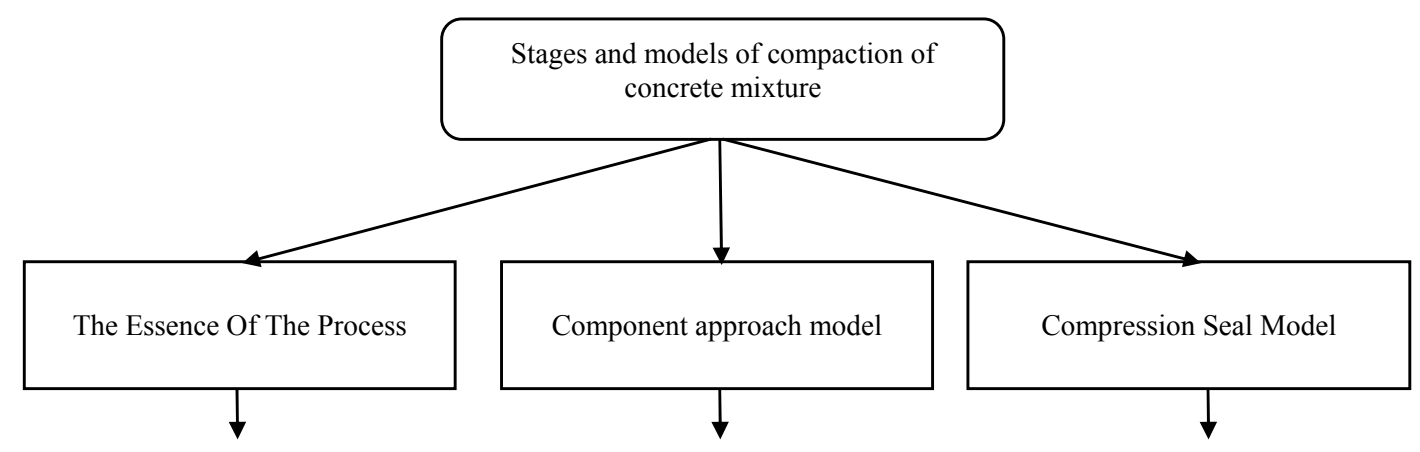

Characteristics of the processes taking place in the concrete mix

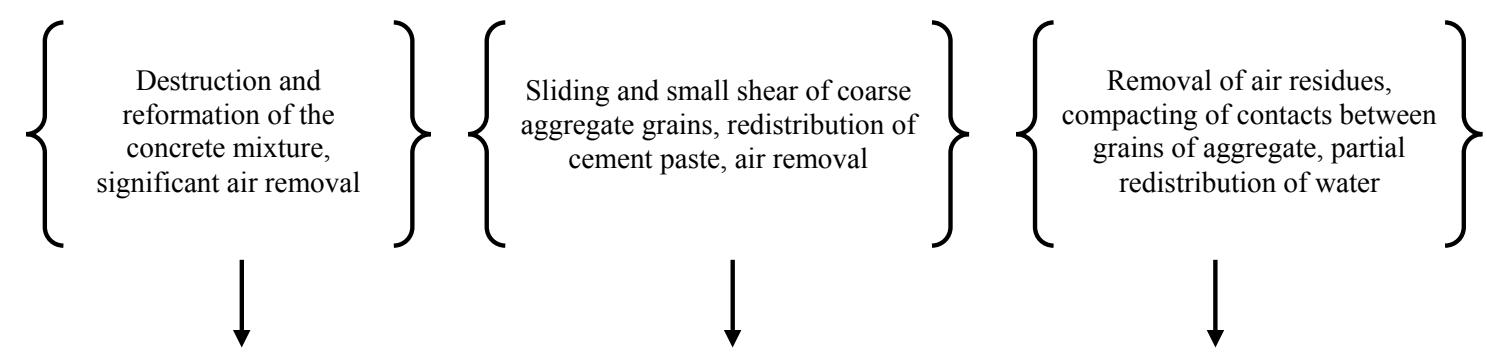

Rheological models of concrete mix behavior
1. Discrete;
2. Elastic-viscous;
3. Elastic-plastic;
4. Elastic-viscous-plastic.

1. Elastic-viscous-plastic;

2. Discrete-continual.
1. Elastic;

2. Elastic-viscous-plastic;

3. Continuous.

Fig. 1. The stages of compaction of concrete mixture, characteristics and rheological models

5. Results of studies of environments processing by low-frequency and high-frequency actions 5. 1. Investigation of the motion of particles in environment based on a discrete model The choice of a mathematical model for determining the motion of a particle in environment is based on taking into account the following parameters: $\mathrm{m}-$ the mass of the particle; $\mathrm{m}_{\mathrm{m}}-$ the mass of the environment in a volume equal to the volume of the particle; $\rho$ - the particle density; $\rho_{0}-$ the density of the environment. Then, on the basis of taking into account the acting forces, the equation of motion of the particle will have the form:

$$
m \ddot{x}_{p}=m_{c}\left(\frac{\rho}{\rho_{0}}-1\right)\left(g-\ddot{x}_{m}\right)+F_{m},
$$

where $\ddot{x}_{\mathrm{p}}-$ the particle acceleration relative to the environment; $\ddot{\mathrm{x}}_{\mathrm{m}}-$ acceleration of the environment at a point coinciding with the center of gravity of the particle; $g$ - the acceleration due to gravity; $\mathrm{F}_{\mathrm{m}}$ - the force with which the environment acts on the particle.

Equations (1), in contrast to the classical ones, take into account the ratio of densities and the effect of gravitational forces and describe the motion of a particle under the condition of a decrease in friction at the points of contact between the particles. Particles under the action of gravitational forces, freed from friction, occupy free space. Let's believe that at the initial stage of consolidation, the forces of dry friction prevail. At the final stage of compaction, viscous friction forces predominate. So the process of compacting the concrete mix is assumed. Proceeding from this, the force $\mathrm{F}_{\mathrm{m}}$, with which the environment acts on the particle, will determine the resistance forces. In the first stage of compacting with dry friction between the particles, the force $\mathrm{F}_{\mathrm{m}}$ : 


$$
\mathrm{F}_{\mathrm{m}}=-\mathrm{m}_{\mathrm{a}} \ddot{\mathrm{x}}_{\mathrm{p}}+\mathrm{F}(\dot{\mathrm{x}})
$$

where $m_{a}-$ the adjoint mass; $F(\dot{x})$ - the resistance force to the relative motion of the particle.

$$
\mathrm{F}(\dot{\mathrm{x}})=0 \text { at } \dot{\mathrm{x}}=0 .
$$

The novelty (2) consists in the method of $\mathrm{m}_{\mathrm{a}}$ determination. Taking into account (2) the equation of motion of the particle (1) takes the form:

$$
\left(m+m_{a}\right) \ddot{x}_{p}=m_{m}\left(\left(\rho / \rho_{0}\right)-1\right)\left(g-\ddot{x}_{m}\right)+F(\dot{x}) .
$$

Let's accept the condition that the particle carries out its motion along circular trajectories in the horizontal plane. Then the projections on the axis oxyz of the absolute velocity of an unperturbed environment near the particle are described by the following dependences:

$$
\dot{\mathrm{x}}_{\mathrm{mx}}=-\mathrm{A}_{0} \omega \sin (\omega \mathrm{t}+\beta) ; \dot{\mathrm{x}}_{\mathrm{my}}=\mathrm{A}_{0} \omega \cos (\omega \mathrm{t}+\beta) ; \dot{\mathrm{x}}_{\mathrm{mz}}=0
$$

where $A_{0}$ - the amplitude of the circular oscillation trajectory; $\omega$ - the oscillation frequency; $\beta-$ the initial phase. Since the most effective technique is the relative evaluation of the process, let's determine the ratio of the resistance forces. Accept: $\mathrm{F}_{\text {hor }}$ - the modulus of the resistance force when moving in a horizontal position; $\mathrm{F}_{\mathrm{ver}}$ - the modulus of resistance force with relative motion in the vertical direction. Then the condition for the motion of the particle in the projections onto the moving axes of coordinates is represented by the ratio of forces and density in the dimensionless form:

$$
\frac{F_{\text {ver }}}{m_{m} g}>\left|\frac{\rho}{\rho_{0}}-1\right| \geq \frac{1}{\sqrt{\left(\frac{m_{m} A_{0} \omega^{2}}{F_{\text {gor }}}\right)^{2}+\left(\frac{m_{m} g}{F_{v e r}}\right)^{2}}}
$$

Analysis of the obtained dependences on the basis of taking into account the numerical values entering into condition (5) is evidence of the possibility of estimating the process of particle motion in environment. Under the conditions (5), particles with a density $\rho>\rho_{0}$ are immersed in environment, that is, they move downward. Under the conditions $\rho<\rho_{0}$, the particles move upward. The practical value of the obtained results (1)-(5) consists in determining the effect of parameters under conditions of rational flow of the first stage of the working process of compacting a concrete mixture. At this stage of compaction, the frequencies $\mathrm{f}=10-15 \mathrm{~Hz}$ are effective, and the numerical values of the amplitudes of the oscillations must vary within the limits $A=0.8-1.5 \mathrm{~mm}$. The reduced dimensionless relations appearing in (5) are criteria for estimating the motion of particles based on the use of a discrete model.

\section{2. Study of the environment motion on the basis of the continuum model}

\section{2. 1 . The second stage of compacting the concrete mix}

In the second stage of compaction, where viscous resistance dominates, the environment becomes a compact structure. The motion of the environment is described by the continuum model proposed by the authors (Fig. 2).

When the pulse passes, the layer of particles with the coordinate $z_{1}$ will shift by the amount $\mathrm{x}$, and the layer with the coordinate $\mathrm{z}_{2}$ by the amount:

$$
\mathrm{x}+\frac{\partial \mathrm{x}}{\partial \mathrm{z}} \Delta \mathrm{z}
$$

Then the volume of the element that contains all the particles that are between $z_{1}$ and $z_{2}$ will be: 


$$
\mathrm{ab}\left(\mathrm{x}_{2}+\mathrm{x}+\frac{\partial \mathrm{x}}{\partial \mathrm{z}} \Delta \mathrm{z}\right)-\mathrm{ab}\left(\mathrm{x}_{1}+\mathrm{x}\right)=\mathrm{ab}\left(1+\frac{\partial \mathrm{x}}{\partial \mathrm{z}}\right) \Delta \mathrm{z}=\Delta \mathrm{v}+\delta \mathrm{v}=\Delta \mathrm{v}\left(1+\frac{\delta \mathrm{v}}{\Delta \mathrm{v}}\right)
$$

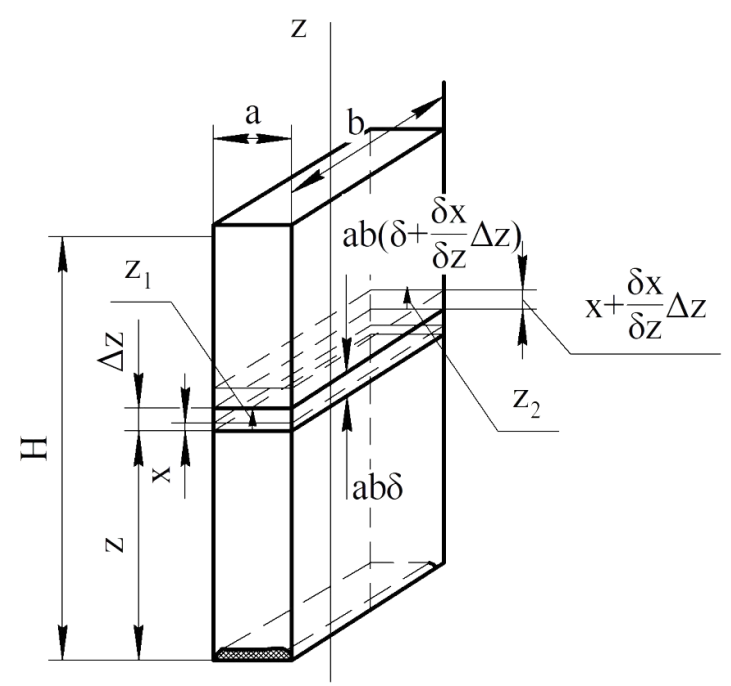

Fig. 2. Scheme of the selected element in the environment

The size $\delta v / \Delta v$ is the relative deformation of the environment. Let's accept the condition for continuity of the environment, that is, the continuity condition is satisfied in the form:

$$
\frac{\delta \mathrm{v}}{\Delta \mathrm{v}}=\frac{\partial \mathrm{x}}{\partial \mathrm{z}}=-\frac{\delta \rho}{\rho_{0}}
$$

Let's compose the equations of motion of the volume element $\Delta v$ from the pulse action. Let's suppose that the velocity and velocity gradient of particles are much less than the speed of sound, and instead of full acceleration, let's take only the local acceleration $\partial \mathrm{x} / \partial \mathrm{t}=\mathrm{x}$. Due to the displacement there is a force of inertia, which causes a reaction force equal to

$$
\rho \Delta \mathrm{zab} \frac{\partial \mathrm{x}}{\partial \mathrm{t}}=\rho \mathrm{ab} \Delta \mathrm{z} \frac{\partial^{2} \mathrm{x}}{\partial \mathrm{t}^{2}}
$$

The external force of the external pressure acting on the element will be:

$$
\mathrm{ab} \sigma-\mathrm{ab}\left(\sigma+\frac{\partial \sigma}{\partial \mathrm{z}} \Delta \mathrm{z}\right)=\mathrm{ab} \frac{\partial \sigma}{\partial \mathrm{z}} \Delta \mathrm{z}
$$

The law of deformation of the environment is represented by the Kelvin-Voigt model:

$$
\sigma=\mathrm{E} \varepsilon+\eta \frac{\mathrm{d} \varepsilon}{\mathrm{dt}}
$$

where $\sigma$ - the voltage; $\varepsilon$ - the relative deformation of the element; $\varepsilon=\partial \mathrm{x} / \partial \mathrm{z} ; \mathrm{E}-$ modulus of elasticity; $\eta$ - the coefficient of viscous properties of the environment.

Substituting the values of (8) in (7) let's obtain the expression for the total force of pressure on the element $\Delta \mathrm{v}$ :

$$
-a b \frac{\partial \sigma}{\partial z} \Delta z=-a b \Delta z\left(\frac{E \partial^{2} x}{\partial z^{2}}+\eta \frac{\partial^{2} t}{\partial^{2} z \partial t}\right)
$$


Equations of motion taking into account all forces will take the form:

$$
\rho a l \frac{\partial^{2} x}{\partial t^{2}} \Delta z-a b \Delta z\left(\frac{E \partial^{2} x}{\partial z^{2}}+\eta \frac{\partial^{3} x}{\partial^{2} z \partial t}\right)=0
$$

Reducing by $\Delta v$, let's obtain:

$$
\rho \frac{\partial^{2} x}{\partial t^{2}}=\left(\frac{E \partial^{2} x}{\partial z^{2}}+\eta \frac{\partial^{3} x}{\partial^{2} z \partial t}\right)
$$

or

$$
\frac{E}{\rho} \frac{\partial^{2} x}{\partial z^{2}}+\frac{\eta}{\rho} \frac{\partial^{3} x}{\partial^{2} z \partial t}=\frac{\partial^{2} x}{\partial t^{2}} .
$$

Equation (9) is the wave equation of an elastic-viscous environment.

Let's consider the oscillations of the environment under the action of periodic pulses without allowance for dissipation. Then the wave equation can be written in the following form:

$$
\frac{\partial^{2} x}{\partial t^{2}}=C^{2} \frac{\partial^{2} x}{\partial z^{2}}
$$

point $\mathrm{z}$ at time $\mathrm{t}$ with respect to the initial position. To determine the function $\mathrm{x}(\mathrm{z}, \mathrm{t})$, it is necessary to specify the initial and boundary conditions. At the initial moment, the environment is at rest, and the velocities are zero. This condition can be written in the form:

$$
x(z, 0)=0 ; x_{t}(z, 0)=0 .
$$

The boundary conditions at the point $\mathrm{x}=\mathrm{H}$ determine the absence of normal stresses, since it is a condition of the free end:

$$
\mathrm{x}_{\mathrm{x}}(\mathrm{H}, \mathrm{t})=0 .
$$

If denote $\mathrm{K}_{\mathrm{a}}(\mathrm{t})$ of the displacement of the lower face $\mathrm{z}=0$ at time $\mathrm{t}$, then the boundary condition for $\mathrm{x}(\mathrm{z}, \mathrm{t})$ for $\mathrm{z}=0$ will have the form:

$$
x(0, t)=K_{a}(t)
$$

Thus, we have at the following problem:

$$
\begin{gathered}
\frac{\partial^{2} \mathrm{x}}{\partial \mathrm{t}^{2}}=\mathrm{c}^{2} \frac{\partial^{2} \mathrm{x}}{\partial \mathrm{z}^{2}} ; \mathrm{x}(\mathrm{z}, 0)=0 ; \mathrm{x}_{\mathrm{t}}(\mathrm{z}, 0)=0 ; \\
\mathrm{x}_{\mathrm{x}}(\mathrm{H}, \mathrm{t})=0 ; \mathrm{x}(0, \mathrm{t})=\mathrm{K}_{\mathrm{a}}(\mathrm{t}) .
\end{gathered}
$$

This problem is solved by the method of propagating waves. The general solution of equation (11) has the form:

$$
x(z, t)=f_{1}(z+c t)+f_{2}(z-c t),
$$

where $\mathrm{f}_{1}(\mathrm{z})$ and $\mathrm{f}_{2}(\mathrm{z})$ - functions determined from the initial and boundary conditions.

For $\mathrm{t}<\mathrm{H} / \mathrm{c}$, the solution (12) can be written in the form: 


$$
x(z, t)=k_{a}\left(t-\frac{z}{c}\right)
$$

where

$$
\mathrm{k}_{\mathrm{a}}(\mathrm{t})= \begin{cases}0 & \text { at } \mathrm{t}<0 \\ \mathrm{k}_{\mathrm{a}}(\mathrm{t}) & \text { at } \mathrm{t}>0\end{cases}
$$

Expression (13) is a forward wave of the pulse propagating with a velocity c from the moving boundary $z=0$. It is easy to see that, because of the interference of the pulse wave at the free end, the solution (30) does not satisfy the boundary condition at $\mathrm{z}=\mathrm{H}$ at $\mathrm{t} \geq \mathrm{H} / \mathrm{c}$. At this point $\mathrm{x}_{\mathrm{x}}(\mathrm{H}, \mathrm{t})=0$.

This boundary condition ensures the motion of the wave in the same phase. For $H / c \leq t<2 H / c$, the solution in the form of a sum of two functions:

$$
\mathrm{x}(\mathrm{z}, \mathrm{t})=\mathrm{k}_{\mathrm{a}}\left(\mathrm{t}-\frac{\mathrm{z}}{\mathrm{c}}\right)+\mathrm{k}_{\mathrm{a}}\left(\mathrm{t}-\frac{\mathrm{H}+\mathrm{z}}{\mathrm{c}}\right)
$$

The solution (14) satisfies the boundary condition for a given time interval $H / c \leq t<2 H / c$. In the section $\mathrm{z}=\mathrm{H}$ at $\mathrm{t} \geq 2 \mathrm{H} / \mathrm{c}$, the solution (14) does not satisfy the condition at the boundary $\mathrm{z}=0$. This is stipulated by the presence of a backward wave. Therefore, under the condition $2 \mathrm{H} / \mathrm{c} \leq \mathrm{t}<3 \mathrm{H} / \mathrm{c}$, the solution of the problem is represented in the form of three functions:

$$
x(z, t)=k_{a}\left(t-\frac{z}{c}\right)+k_{a}\left(t-\frac{2 H-z}{c}\right)-k_{a}\left(t-\frac{2 H+z}{c}\right) .
$$

For the condition $3 \mathrm{H} / \mathrm{c} \leq \mathrm{t}<4 \mathrm{H} / \mathrm{c}$, let's obtain:

$$
\begin{aligned}
& x(z, t)=k_{a}\left(t-\frac{z}{c}\right)+k_{a}\left(t-\frac{2 H-z}{c}\right)- \\
& -k_{a}\left(t-\frac{2 H+z}{c}\right)-k_{a}\left(t-\frac{4 H-z}{c}\right) .
\end{aligned}
$$

$\mathrm{k}_{\mathrm{a}}\left(\mathrm{t}-\frac{\mathrm{z}}{\mathrm{c}}\right)$ - straight wave coming from a moving boundary;

$\mathrm{k}_{\mathrm{a}}\left(\mathrm{t}-\frac{2 \mathrm{H}-\mathrm{z}}{\mathrm{c}}\right)-$ a pulse wave reflected from the boundary $\mathrm{z}=\mathrm{H}$;

$-\mathrm{k}_{\mathrm{a}}\left(\mathrm{t}-\frac{2 \mathrm{H}+\mathrm{z}}{\mathrm{c}}\right)-$ pulse wave reflected from the boundary $\mathrm{z}=0$;

$-\mathrm{k}_{\mathrm{a}}\left(\mathrm{t}-\frac{4 \mathrm{H}-\mathrm{z}}{\mathrm{c}}\right)$ - wave reflected from $\mathrm{z}=0$, and then reflected from the boundary $\mathrm{z}=\mathrm{H}$ in

the same phase. Thus, for any instant $t$ of the solution of problem (16) has the form:

$$
\mathrm{x}(\mathrm{z}, \mathrm{t})=\sum_{\mathrm{n}=1}^{\infty}\left[\mathrm{k}_{\mathrm{a}}\left(\mathrm{t}-\frac{\mathrm{z}+2 \mathrm{nH}}{\mathrm{c}}\right)-\mathrm{k}_{\mathrm{a}}\left(\mathrm{t}+\frac{\mathrm{x}-2 \mathrm{nH}}{\mathrm{c}}\right)\right](-1)^{\mathrm{n}}+\mathrm{k}_{\mathrm{a}}\left(\mathrm{t}-\frac{\mathrm{z}}{\mathrm{c}}\right) .
$$

Accordingly, for each fixed $t$, let's obtain a finite sum, since $K_{a}(t)=0$ for $t<0$. This is the sum of the displacements from the direct wave of the wave pulse reflected from the boundary $\mathrm{x}=\mathrm{H}$ (free end) and $z=0$. When the wave is reflected from the lower boundary, a phase shift occurs, and reflection from the upper boundary $\mathrm{z}=\mathrm{H}$ occurs in the same phase. This explains the presence under the summation sign of the factor (1). The above dependences are valid for environment without allowance for dissipation. Allowance for dissipation in the passage of plane waves in an elastic 
viscous environment leads to the following dependence for the displacement at any point of the environment $\mathrm{z}$ at time $\mathrm{t}$ :

$$
\begin{aligned}
& x(z, t)=\sum_{n=1}^{\infty}\left[k_{a}\left(t-\frac{x+2 n H}{c}\right) e^{-k_{f}^{*}(x+2 n H)}-k_{a}\left(t+\frac{x-2 n H}{c}\right) e^{-k_{f}^{*}(2 n H-z)}\right] x \\
& x(-1)^{n}+k_{a}\left(t-\frac{x}{c}\right) e^{-k_{f}^{*} z} .
\end{aligned}
$$

Expression (18) is a new relationship that determines the motion of layers in the implementation of any processing mode of the technological environment. For the approximate solution of problems with significant attenuation, (n>1) expression (18) is simplified to the form:

$$
x(z, t)=k_{a}\left(t-\frac{x}{c}\right) e^{-k_{f}^{*} z}+k_{a}\left(t+\frac{x-2 n H}{c}\right) e^{-k_{f}^{*}(2 n H-z)} k_{a}\left(t-\frac{x+2 n H}{c}\right) e^{-k_{f}^{*}(x+2 n H)} .
$$

The solution (19) makes it possible to determine the displacement at some point along the height of the column of the mixture. Analysis of the obtained dependences on the effective realization of the second stage of compaction indicates the need for a significant increase in the frequency within $\mathrm{f}=35-50 \mathrm{~Hz}$. At the same time, an effective condition for preventing stratification of the mixture is a decrease in the amplitude of the oscillations to values $A=0.35-0.5 \mathrm{~mm}$. The reliability of certain parameters is estimated by the performed experiments, which are given below.

\section{2. 2. Investigation of the influence of parameters of cavitation processing of the envi-} ronment on the basis of the continual model application

In determining the parameters of the influence of cavitation technology on the environments processing, the following hypothesis is accepted. It is assumed that the main parameter of influence on the processing process is the contact pressure at the boundary of the "cavitator-environment" system. This is due to the fact that pressure is a key parameter in the dependencies for the determination of energy, which is transmitted from the exciter. Calculation formulas for the determination of contact pressure are adopted on the basis of previous studies of one of the authors of this paper [13]. The contact pressure is determined by the formula:

$$
\mathrm{p}=\rho \mathrm{lA} \omega^{2} \overline{\mathrm{x}}
$$

where $\rho$ - the density of the environment; 1 - the length of the environment in the direction of propagation of the longitudinal wave; $\mathrm{A}$ - the amplitude of the oscillations of the - contact zone of the "cavitator-environment" system; $\chi=\sqrt{\chi_{1}^{2}+\chi_{2}^{2}}$ - coefficients of wave action on the contact pressure:

$$
\chi_{1}=\frac{\alpha \operatorname{sh} 2 \alpha 1+\beta \sin 2 \beta 1}{1\left(\alpha^{2}+\beta^{2}\right)[\operatorname{ch} 2 \alpha 1+\cos 2 \beta 1]} ; \quad \chi_{2}=\frac{\alpha \sin 2 \beta 1-\beta \operatorname{sh} 2 \alpha 1}{1\left(\alpha^{2}+\beta^{2}\right)[\operatorname{ch} 2 \alpha 1+\cos 2 \beta 1]} ;
$$

where $\alpha, \beta$ - coefficients of influence of the ratio $\omega / \mathrm{c}$ and $\gamma$ the magnitude and rate of extinction of wave propagation:

$$
\alpha=\frac{\omega}{c} \sqrt{\frac{\sqrt{1+\gamma^{2}-1}}{2\left(1+\gamma^{2}\right)}} ; \beta=\frac{\omega}{c} \sqrt{\frac{\sqrt{1+\gamma^{2}}+1}{2\left(1+\gamma^{2}\right)}}
$$

$\gamma$ - loss factor, which estimates the level of energy dissipated in the environment in one oscillation cycle. An important parameter of the impact process is also the propagation velocity of waves with:

$$
c=\sqrt{\mathrm{E} / \rho},
$$


where $\mathrm{E}$ - the elasticity modulus of the environment, which has a density $\rho$. It is the velocity of wave propagation along the physical content that determines the ratio of elastic (E) and mass $(\rho)$ characteristics of the environment, as a definite influence on the process of its cavitation. If the dependence (23) is mainly used for elastic environments, then for liquids saturated with gas, the formula [13] is used:

$$
c=1 / \sqrt{\rho \beta_{\mathrm{ac}}}
$$

where $\beta_{\mathrm{ac}}$ - the adiabatic compressibility. Comparing (23) and (24), it can be noted that the parameters $E$ and $\beta_{\mathrm{ac}}$ themselves correlate: $\beta_{\mathrm{ac}}=1 / \mathrm{E}$. The sign parameter is the amplitude of the oscillations of the contact zone A. The calculations of the pressure $\mathrm{p}$ as a function of the velocity $\mathrm{c}$ for the characteristic values of the amplitude of the oscillations are done (Fig.3).

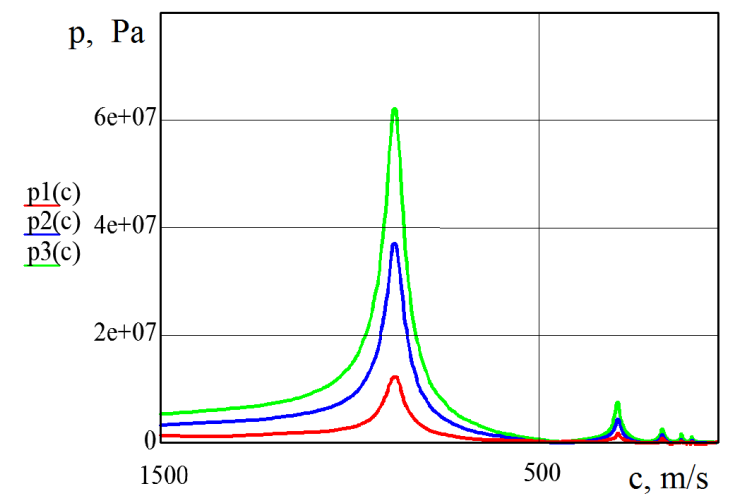

Fig. 3. Graphs of the dependence of contact pressure (p) with the change in velocity (c) of the flow of cavitation water treatment: $\mathrm{p} 1$ - amplitude $4 \times 10^{-6} \mathrm{~m} ; \mathrm{p} 2-12 \times 10^{-6} \mathrm{~m} ; \mathrm{p} 3-20 \times 10^{-6} \mathrm{~m}$

The rate varied from the beginning of the stage of formation of cavitation process in the stage of scooping the bubbles in the water. The graphs are given for the first time and show the complicated process of the cavitation process. At values of the wave propagation velocity $\mathrm{c}=643 \mathrm{~m} / \mathrm{s}$ resonance bursts of pressure are manifested, as well as at the stage of developed cavitation $(\mathrm{c}=312 \mathrm{~m} / \mathrm{s})$. The presence of such character and numerical values of pressures primarily depends on the initial and boundary conditions. The value of the modulus of elasticity and density of the environment also affect the concrete stage of the cavitation process. To intensify the course of the stages of the cavitation process, ultrasonic resonance flow cavitators are created [14] (Fig. 4).
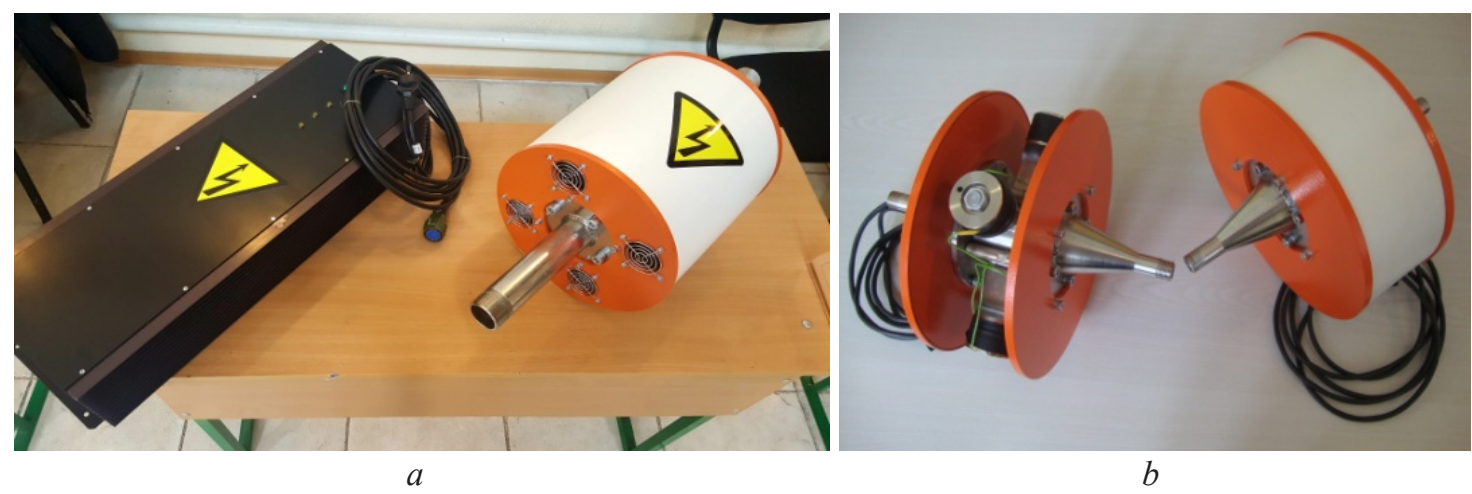

Fig. 4. Ultrasonic flow cavitators: $a$ - USS-1200, $b$ - USS-400

These are the new developed devices, which for the first time in the practice of applying cavitation technology, calculated on the basis of the application of the wave theory. Cavitation chamber of installation is cylindrical. Ultrasonic resonant drive-emitters are placed on the gen- 
erating surface. At the heart of the ultrasonic resonance drive-emitter is a half-wave piezoelectric Langevin transducer. When excitation of resonance drives, the phase of connection of the drives to the electric oscillator was taken into account.

\section{Experimental studies of the compacting processes of the environment}

The process of compaction of the concrete mixture was studied in an installation with variable parameters and fixing the stage (Fig. 4). The method was intended to implement a shift mode of a two-stage process on a constructed installation (Fig. 5, a) and on a standard laboratory vibrating plate CMЖ-539 (Chelyabinsk plant Dormashina, Russia) with constant parameters (oscillation frequency $\mathrm{f}=50 \mathrm{~Hz}$, amplitude $\mathrm{A}=0,45 \mathrm{~mm}$ ).

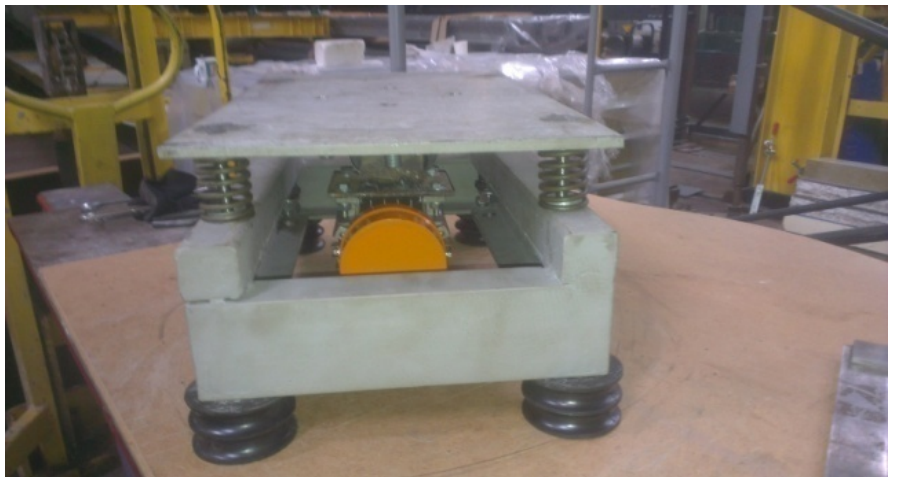

$a$

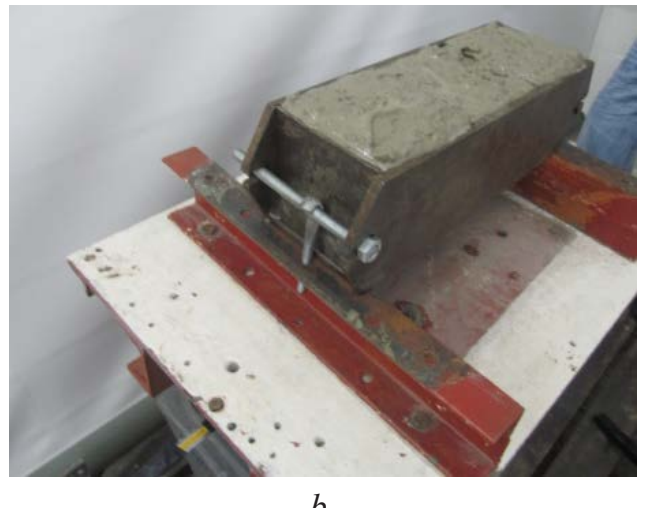

$b$

Fig. 5. Designed installation: $a$ - an experimental vibration unit; $b$ - molded concrete sample

The main task is comparison of the results of compacting the concrete mixture obtained at two plants. At the first stage, the compaction process at the variable-parameter plant is carried out at a frequency $\mathrm{f}=15 \mathrm{~Hz}$. At the second stage, the frequency increased to $\mathrm{f}=48 \mathrm{~Hz}$, and the amplitude of the oscillations decrease. On the standard vibration platform, the parameters are constant. The parameters are recorded on the computer display. Typical vibrograms obtained in the experimental vibration set are shown in Fig. 6.
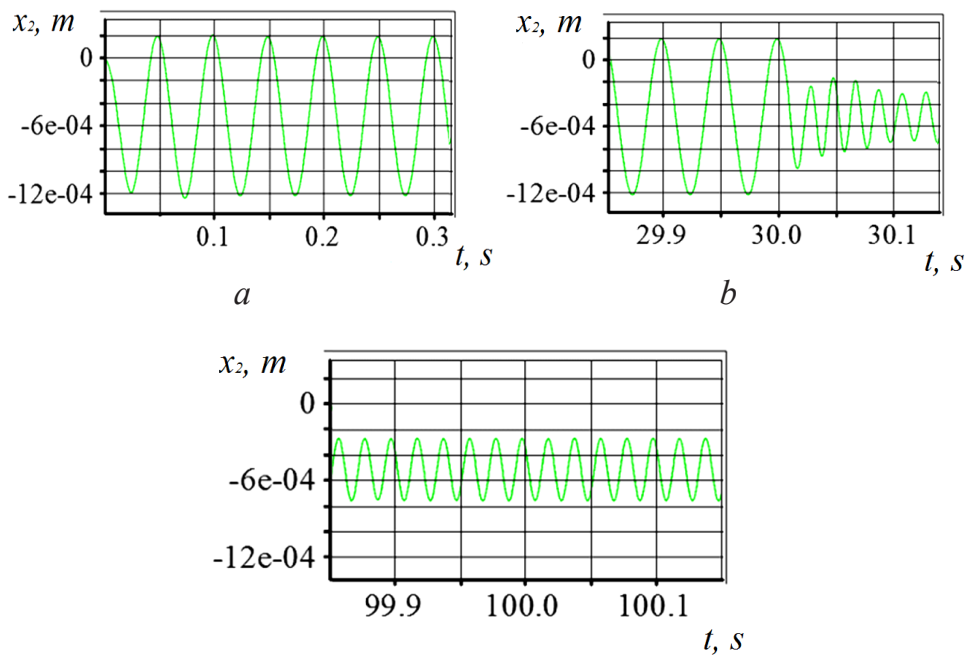

c

Fig. 6. Vibrograms for changing the amplitude of oscillations of the system: $a$ - the first stage of the process; $b$ - transient mode; $c$ - the second stage

The vibrations show the change in the amplitude of the oscillations during the realization of various stages of the mixture compaction. At the first stage (Fig. 6, a), a regime with an amplitude 
of oscillations $A=1.2 \mathrm{~mm}$ is realized. In the future (Fig. 6, b), a transitional regime occurs, and the second stage of compaction is realized (Fig. 6, c) with an amplitude of oscillations $A=0.45 \mathrm{~mm}$. Due to this mode the compaction time decreased from 2 minutes to 1.2 minutes. Molded samples of concrete on a standard vibration platform and on the experimental with a variable mode of oscillation are shown in Fig. 6. Molded concrete samples on a standard vibration platform and on the experimental with a variable mode of oscillation are shown in Fig. 7.

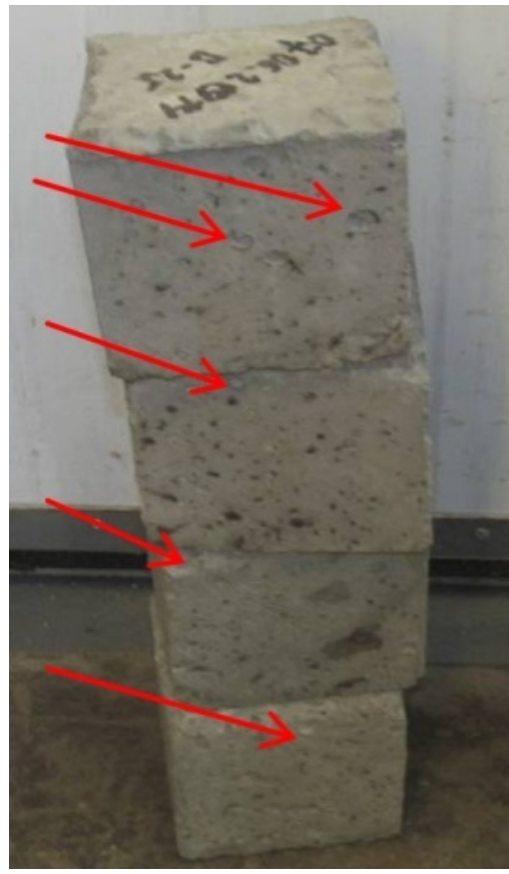

$a$

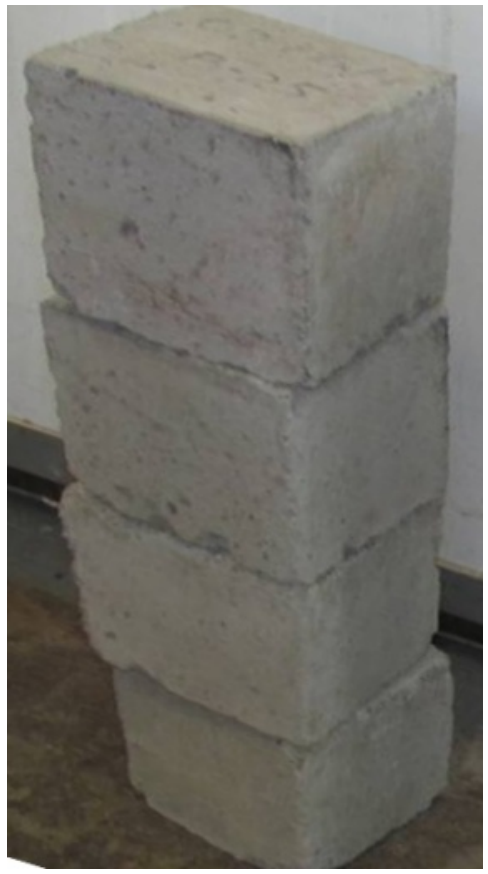

$b$

Fig. 7. General view of the molded concrete samples: $a-$ on a standard platform; $b-$ on the experimental installation

The molded samples are compared among themselves. On the samples (Fig. 7, $\boldsymbol{a}$ ) the undercompaction zones are visible (pores and shells, shown by red arrows). On the samples of concrete (Fig. 7, b) there is a significant improvement in appearance. Studies of the strength of concrete samples are done. The concrete samples molded in the experimental installation have strengths of $18 \%$ more than those of the standard site.

\section{Discussion of the results of the study of the influence of low-frequency and high-frequency actions on the environments processing}

Analytic dependencies describing the process of environments motion from discrete and continuum models obtained as a result of research are new. A new principle for processing technological environments with variable parameters and regimes at each stage with an evaluation of the effect of the effect is established. In the first stage, the process of compacting the concrete mixture is carried out at a frequency $\mathrm{f}=15 \mathrm{~Hz}$. Processing at low frequencies reduces energy costs. In the second stage, the frequency increases to the value $\mathrm{f}=48 \mathrm{~Hz}$, and the amplitude of the oscillations decreases by a factor of 1.5. The compaction time decreased from 2 minutes to 1.2 minutes. The use of such modes and parameters allows to obtain concrete of necessary density and increased strength by $18 \%$. For the first time, the change in contact pressure at the whole stage of high-frequency cavitation processing is determined by the example of water as a technological environment. Completed research is fundamentally new. The realization of the technological process of processing makes it possible to reduce the processing time by $40 \%$. The obtained amplitudes and frequencies of oscillations at low-frequency modes provide an increase in the strength of the material by $18 \%$. Considering the techno- 
logical processes associated with the use of cavitation, one of the main tasks is obtaining the maximum effect by successfully combining the energies of the cavitator and the environment into a single optimized synergetic system. The application of high-frequency cavitation modes with the possibility of taking into account higher harmonics is a promising direction. Experimental studies are required on environments with different viscosities. The results of research into the physics of environments processing are used in calculating the modes and parameters of exciters. The obtained results are given for environments with elastic-viscous properties. There are materials with other laws of changing dissipative properties. In this there is a certain lack of performed research. Now, further research is planned as a continuation of the topic under consideration for materials with other rheological properties. The obtained analytical dependencies are proposed to be used for the study of other technological environments.

\section{Conclusions}

1. The motion of particles of environment with a discrete model that takes into account the change in density and the influence of gravitational forces is investigated. By the continuum model of motion, an analytical dependence is obtained, which makes it possible to determine the amplitude of the oscillations of a layer of the environment in the direction of the force action.

2. Two stages of the frequency regime for compaction of concrete mixtures by a pulsed low-frequency load are determined. At the first stage, the frequency $\mathrm{f}=15 \mathrm{~Hz}$ is proposed, at the second stage $\mathrm{f}=48 \mathrm{~Hz}$.

3. New ultrasonic flow cavitators are created for processing disperse liquid environments, taking into account the resonance of the oscillatory system.

\section{References}

[1] Sudarshan, N. M., Chandrashekar Rao, T. (2017). Vibration Impact on Fresh Concrete of Conventional and UHPFRC. International Journal of Applied Engineering Research, 12 (8), 1683-1690.

[2] Ruchynskyi, M. M., Sviderskyi, A. T., Diedov, O. P. (2011). Teoriia i praktyka stvorennia vibratsiinykh mashyn na osnovi tsilespriamovanoho vrakhuvannia dyskretno-kontynualnykh vlastyvostei robochykh orhaniv i obrobliuvalnykh seredovyshch. Visnyk Kremenchutskoho natsionalnoho universytetu imeni Mykhaila Ostrohradskoho, 3 (1 (68)), 102-104.

[3] Nazarenko, I. I., Martyniuk, I. Yu. (2014). Issledovanie dinamiki vibratsionnoi ploshchadki dlia formovaniia standartnyh kubikov betona. Mechanization of construction, 3, 29-31.

[4] Xi, X., Cegla, F., Mettin, R., Holsteyns, F., Lippert, A. (2012). Collective bubble dynamics near a surface in a weak acoustic standing wave field. The Journal of the Acoustical Society of America, 132 (1), 37-47. doi: 10.1121/1.4726009

[5] Luhovskyi, O. F., Movchaniuk, A. B., Bernyk, I. M. (2011). Doslidzhennia zvukovoho polia ta tekhnolohichnykh mozhlyvostei rezonansnoho kavitatora pry obrobtsi ridynno-dyspersnykh seredovyshch. Promyslova hidravlika i pnevmatyka, 1, 44-47.

[6] Bernyk, I. (2016). Research parameters of ultrasound processing equipment dispersed in a technological environment. MOTROL. Commission of Motorization and Energetics in Agriculture, $18(3), 3-13$.

[7] Gallego-Juarez, J. A. (2010). High-power ultrasonic processing: Recent developments and prospective advances. Physics Procedia, 3 (1), 35-47. doi: 10.1016/j.phpro.2010.01.006

[8] Thomas, J.-L. (2004). Inhomogeneous pressure field inside a collapsing bubble accelerated by an acoustic pulse. Physical Review E, 70 (1), 016305. doi: 10.1103/physreve.70.016305

[9] Cheng, H. Y., Chu, M.-C., Leung, P. T., Yuan, L. (1998). How important are shock waves to single-bubble sonoluminescence? Physical Review E, 58 (3), R2705-R2708. doi: 10.1103/physreve. 58.r2705 
[10] Moshaii, A., Sadighi-Bonabi, R. (2004). Role of liquid compressional viscosity in the dynamics of a sonoluminescing bubble. Physical Review E, 70 (1), 016304. doi: 10.1103/physreve. 70.016304

[11] Toegel, R., Luther, S., Lohse, D. (2006). Viscosity Destabilizes Sonoluminescing Bubbles. Physical Review Letters, 96 (11), 114301. doi: 10.1103/physrevlett.96.114301

[12] Toegel, R., Lohse, D. (2003). Phase diagrams for sonoluminescing bubbles: A comparison between experiment and theory. The Journal of Chemical Physics, 118 (4), 1863-1875. doi: 10.1063/1.1531610

[13] Bernyk, I. (2017). Theoretical aspects of the formation and the development of cavitation processes in a technological environment. MOTROL. Commission of Motorization and Energetics in Agriculture, 19 (3), 3-12.

[14] Lugovskoy, O. F., Movchanuk, A. V., Gryshko, I. A. (2014). Possibility of application flowing tubular kavitator with high ultrasonic intensity oscillations for processing of the liquid environments. Vibration in engineering and technology, 2, 125-130. 